\title{
REPLACEMENT PERIPHERAL INTRAVENOUS CATHETERS WITH CLINICAL INDICATION FOR PATIENT CONVENIENCE, COST EFFICIENCY AND REDUCING NURSES WORKLOAD
}

\author{
Narmawan ${ }^{1}$, Ida Djafar ${ }^{2}$, Hasnani Hakim ${ }^{3}$, Harmiati Syafril $^{3}$, Syahrul $^{4}$, Syahrul \\ Ningrat ${ }^{5}$
}

\author{
${ }^{1}$ Program Studi S1 Ilmu Keperawatan Stikes Karya Kesehatan Kendari, Kendari \\ ${ }^{2}$ Politeknik Kesehatan Kemenkes Maluku, Maluku \\ ${ }^{3}$ RSUD Bulukumba, Bulukumba \\ ${ }^{4}$ Bagian Keperawatan Komunitas dan Keluarga, Fakultas Keperawatan, Universitas Hasanuddin, \\ Makassar \\ ${ }^{5}$ Bagian Keperawatan Medikal Bedah, Fakultas Keperawatan, Universitas Hasanuddin, Makassar \\ e-mail : narmawanfebson@gmail.com
}

\begin{abstract}
Introduction: PIVCs (Peripheral Intravenous Catheters) have been widely used for clinical medical care which is having risk for phlebitis occurence. IV catheter replacement is performed when there is clinical indication such us phlebitis. The consequence of this action is patient convinence, nurse workload and patient care cost efficiency. Methode: A longitudinal study with experimental results of evidence based practice on replacement of PIVSc with clinical indication as an effort to improve patient convinience, cost efficiency and reduce nurse workload in 41 patients. Result: 41 patients attached PIVCs, 100\% wanted IV catheter replacement if there was any clinical indication. $68 \%$ of patients said very uncomfortable if IV catheter routinely replaced. 16 nurse $(56.25 \%)$ said there is no need to replace IV catheter regularly. $43.75 \%$ of nurses felt IV catheters rountine replacement increased the working time and $50 \%$ of the nurses felt that nurses workload was increased. Conclusions: IV catheter replacement can be performed if there is cinical indication because it can improve patient convenience, increase cost efficiency and reduce nurse workload
\end{abstract}

Key words : peripheral intravenous catheters, patient convinience, cost efficiency, nurses workload.

\section{PENDAHULUAN}

Periferal intravena kateter (Peripheral intravenous catheters/ PIVCs) telah banyak digunakan di seluruh dunia untuk perawatan medis klinis (Gorski \& Phillips, 2014), dan intervensi klinis penting lainnya yang menyelamatkan jiwa (McCallum \& Higgins, 2012). Tindakan pemberian kateter intravena (IV) ini berupa tindakan invasif pada beberapa pembuluh darah vena perifer dengan tujuan untuk memberikan cairan dan elektrolit, untuk menjaga keseimbangan di dalam tubuh, memberikan glukosa yang dibutuhkan untuk metabolisme dan membantu dalam pemberian obat secara IV (Jacob, R, \& Tarachnand, 2014), dengan beberapa risiko komplikasi seperti infeksi, emboli udara, flebitis, malposition, thrombosis vena, oklusi (tersumbat) (Gorski et al., 2016). Oleh karena pemasangan IV merupakan tindakan invasif yang menyakitkan sehingga strategi seperti pengambilan IV yang lebih baik untuk meningkatkan kenyamanan dan keamanan pasien diperlukan untuk memperpanjang fungsi IV termasuk mencegah komplikasi flebitis atau penarikan kateter yang tidak disengaja (Alekseyev et al., 2012). Flebitis merupakan komplikasi yang paling sering dari Peripheral intravenous (Pasalioglu \& Kaya, 2014), yang mungkin terjadi $50 \%$ atau bahkan 75\% (Gorski et al., 2016; RCN (Royal College of Nursing), 2010) pada pasien 
dengan penyakit menular (Dychter, Gold, Carson, \& Haller, 2012).

Munculnya komplikasi terhadap pemasangan IV perifer dideteksi sekitar $41,2 \%$ yang dikaitkan dengan lama terpasang, penggunaan antibiotik, jenis kelamin dan lokasi insersi. Kejadian flebitis meningkat secara independen dengan meningkatnya durasi kateter, rata-rata lebih dari 72 jam (Danski, Oliveira, Johann, Pendrolo, \& Vayego, 2015) dan tertinggi setelah 96 jam (Cicolini et al., 2014). Kondisi flebitis ini dapat ditandai dengan adanya nyeri, eritema, pembengkakan, dan trombosis (Dychter et al., 2012), umumnya disebabkan oleh bakteri osilokokus Staphylococcus aureus (SABs)(Rickard et al., 2015), untuk itu diperlukan penilaian terhadap lokasi akses/penusukkan setiap hari (Gorski et al., 2016; RCN (Royal College of Nursing), 2010). Selain flebitis, tindakan invasif intravena juga menyebabkan lama waktu perawatan, biaya perawatan kesehatan tambahan dan ketidaknyamanan dan morbiditas pasien (McCallum \& Higgins, 2012). Oleh karena itu, kondisi tersebut membutuhkan perawatan atau penggantian kateter IV untuk meningkatkan kenyamanan pasien, sebab flebitis dapat dicegah dengan teknik penyisipan dan perawatan terus menerus, bukan dengan penggantian intravena kateter yang dilakukan secara rutin (Rickard et al., 2015).

Penggantian kateter IV saat terdapat gejala kilinis flebitis seperti halnya adanya nyeri pada situs IV maka penggantian kateter harus segera dilakukan berdasarkan systematik review oleh Morrison \& Holt (2015), didapatan bahwa penggantian kateter IV hanya bila ada indikasi akan menghemat biaya, meningkatkan kepuasan pasien dan mengurangi tindakan invasif yang menyakitkan pasien. Selain itu bukti lain bahwa penggantian kateter intravena perifer lebih aman jika dilakukan apabila ada indikasi klinis, karena penggantian yang ditunjukkan secara klinis akan mencegah hingga 6 juta pemasangan atau insersi kateter intravena yang tidak perlu, dan menghemat sekitar 2 juta jam waktu kerja, dan sampai \$ 60 juta biaya perawatan rumah sakit (Keogh, 2013). Pandangan lain juga dikemukakan oleh Wu \& Casella (2013), bahwa pergantian selang intravena yang dilakukan secara klinis mengurangi beban kerja untuk staf klinis dan biaya perawatan kesehatan. Oleh sebab itu, penelitian ini mengaplikasikan penggantian PIVCs sesuai indikasi klinis dan menilai kenyamanan pasien, beban kerja perawat serta biaya perawatan

\section{METODE}

Desain penelitian yang digunakan dalam penerapan Evidence Based Practice ini adalah eksperimen melalui study kohort longitudinal.

Eksperimen ini dilakukan dengan mempertimbangkan beberapa aspek etik (autonomy, nonmalaficience, beneficence dan justice) dan tanda persetujuan lisan juga telah diperoleh dari responden serta telah ada izin dari pihak RS. Selanjutnya melakukan penilaian terhadap kenyamanan pasien untuk mengevaluasi tingkat kenyamanan pasien terhadap penggantian PIVCs dengan menggunakan instrumen skala kenyamanan pasien secara verbal (Line, 2010). Termasuk evaluasi beban kerja pada 16 orang perawat pelaksana di Ruang perawatan Bedah Ortopedi terhadap penggantian kateter IV.

\section{HASIL}

Eksperiman ini telah kami lakukan dengan mengobservasi pada 41 pasien yang terpasang IV kateter terhadap ada atau tidak adanya indikasi klinis serta penggantian kateter IV jika ada indikasi secara klinis mulai tanggal12 sampai dengan 22 Desember 2017 di RSUP DR. Wahidin Sudirohusodo Makassar. 
A. Karakteristik responden

Adapun karakteristik responden dapat dilihat pada tabel 1

\begin{tabular}{|c|c|c|}
\hline Karakteristik pasien & Frekuensi (f) & Persentase (\%) \\
\hline \multicolumn{3}{|l|}{ Jenis Kelamin } \\
\hline Laki-laki & 28 & 68.30 \\
\hline Perempuan & 13 & 31.70 \\
\hline \multicolumn{3}{|l|}{ Umur } \\
\hline$\leq 30$ tahun & 9 & 21.95 \\
\hline $31-50$ tahun & 18 & 43.90 \\
\hline$\geq 51$ tahun & 14 & 34.15 \\
\hline Karakteristik Perawat & Frekuensi (f) & Persentase (\%) \\
\hline \multicolumn{3}{|l|}{ Jenis Kelamin } \\
\hline Laki-laki & 7 & 43.75 \\
\hline Perempuan & 9 & 56.25 \\
\hline \multicolumn{3}{|l|}{ Umur } \\
\hline 20-30 tahun & 13 & 81.25 \\
\hline 31-40 tahun & 1 & 6.25 \\
\hline$\geq 41$ tahun & 2 & 12.5 \\
\hline \multicolumn{3}{|l|}{ Pendidikan } \\
\hline D3 & 10 & 62.5 \\
\hline $\mathrm{S} 1$ & 1 & 6.2 \\
\hline Ners & 5 & 31.25 \\
\hline \multicolumn{3}{|l|}{ Lama Kerja } \\
\hline$<5$ tahun & 10 & 62.5 \\
\hline 5-10 tahun & 3 & 18.75 \\
\hline$>10$ tahun & 3 & 18.75 \\
\hline
\end{tabular}

Tabel 1. Karakteristik responden (perawat $n=16$, Pasien $n=41$ )

B. Pelepasan dan atau penggantian peripheral intravena kateter (dengan indikasi atau tanpa indikasi klinis)

\begin{tabular}{lcc}
\hline Indikasi klinis/non klinis & Frekuensi (f) & Persentase (\%) \\
\hline$\leq 3$ hari & 9 & 21.95 \\
Pulang & 2 & 4.87 \\
Obat oral & 1 & 2.43 \\
Pindah ruangan & 3 & 7.31 \\
IV lanjut & 7 & 17.07 \\
Phlebitis & 1 & 2.43 \\
Meninggal & 1 & 2.43 \\
IV tercabut & & \\
\hline 3 hari & 8 & 19.51 \\
Pulang & 2 & 4.87 \\
Obat oral & - & - \\
Pindah ruangan & 5 & 12.19 \\
IV lanjut & 2 & 4.87 \\
Phlebitis & - & - \\
Meninggal & - & - \\
IV tercabut & & \\
\hline
\end{tabular}

Tabel 2. Evaluasi penggantian PIVCs $(n=41)$ 


\begin{tabular}{lll}
\hline $\begin{array}{l}\text { Kenyamanan klien dan } \\
\text { penggatian IV }\end{array}$ & ekuensi (f) & $\begin{array}{l}\text { Persentase } \\
(\%)\end{array}$ \\
\hline $\begin{array}{l}\text { Penggantian Kateter } \\
\quad \text { Rutin }\end{array}$ & 0 & 0 \\
$\quad$ Indikasi klinis & 41 & 100 \\
\hline $\begin{array}{l}\text { Kenyamanan Pasien dengan } \\
\text { penggantian IV rutin }\end{array}$ & & \\
$\quad$ Sangat nyaman sekali & 0 & 0 \\
$\quad$ Sedikit nyaman & 0 & 0 \\
$\quad$ Nyaman sedang & 0 & 0 \\
$\quad$ Tidak nyaman & 13 & 32 \\
$\quad$ Sangat tidak nyaman sekali & 28 & 68 \\
\hline
\end{tabular}

Tabel 3. Evaluasi kenyamanan pasien $(n=41)$

C. Penilaian kenyamanan pasien terhadap penggantian peripheral IV kateter jika dilakukan penggantian tiap 3 hari tanpa indikasi klinis

Seratus persen (100\%) pasien yang dirawat dengan kateter IV mengatakan lebih memilih penggantian kateter jika ada indikasi klinis.
Dari segi kenyamanan, 68\% pasien mengatakan sangat tidak nyaman sekali jika penggantian IV dilakukan secara rutin (tabel 3)

D. Penilaian beban kerja perawat terhadap penggantian periferal intravena kateter

Beban kerja perawat terhadap periferal intravena kateter (PIVCs). Dari 16 perawat 43,75\% sering sekali melakukan pemasangan PIVCs. 37,5\% perawat sering dan kadang-kadang melakukan pergantian peripheral intravenous catheters / PIVCs secara rutin (3 hari) sesuai dengan standar prosedur operasional yang berlaku di rumah sakit. $43,75 \%$ perawat kadang-kadang merasa pergantian peripheral intravenous catheters / PIVCs secara rutin (setiap 3 hari) ) membuat waktu kerja bertambah dan $50 \%$ perawat merasa menambah beban kerja. Menurut perawat melakukan pergantian secara rutin tidak perlu dilakukan $(56,25 \%)$ (tabel 4). 


\begin{tabular}{|c|c|c|}
\hline Pernyataan & Jawaban & Frekuensi (\%) \\
\hline $\begin{array}{l}\text { Selama ini saya melakukan pergantian } \\
\text { peripheral intravenous catheters / PIVCs }\end{array}$ & $\begin{array}{c}\text { Sering } \\
\text { Sering Sekali } \\
\text { Kadang Kadang }\end{array}$ & $\begin{array}{c}6(37.5) \\
7(43.75) \\
3(18.75) \\
\end{array}$ \\
\hline $\begin{array}{l}\text { Selama ini saya melakukan pergantian } \\
\text { peripheral intravenous catheters / PIVCs } \\
\text { secara rutin (setiap } 3 \text { hari) }\end{array}$ & $\begin{array}{l}\text { Sering } \\
\text { Kadang-Kadang } \\
\text { Pernah }\end{array}$ & $\begin{array}{l}6(37.5) \\
6(37.5) \\
4(25)\end{array}$ \\
\hline $\begin{array}{l}\text { Selama ini saya merasa pergantian } \\
\text { peripheral intravenous catheters / PIVCs } \\
\text { secara rutin (setiap } 3 \text { hari) membuat } \\
\text { waktu kerja saya bertambah }\end{array}$ & $\begin{array}{l}\text { Kadang-Kadang } \\
\text { Tidak Pernah } \\
\text { Sering } \\
\text { Sering Sekali } \\
\end{array}$ & $\begin{array}{l}7(43.75) \\
4(25) \\
3(18.75) \\
2(12.5)\end{array}$ \\
\hline $\begin{array}{l}\text { Selama ini saya merasa pergantian } \\
\text { peripheral intravenous catheters / PIVCs } \\
\text { secara rutin (setiap } 3 \text { hari) menambah } \\
\text { beban kerja saya }\end{array}$ & $\begin{array}{l}\text { Tidak Pernah } \\
\text { Kadang-Kadang } \\
\text { Sering }\end{array}$ & $\begin{array}{l}6(37.5) \\
8(50) \\
2(12.5)\end{array}$ \\
\hline $\begin{array}{l}\text { Selama ini saya merasa pergantian } \\
\text { peripheral intravenous catheters / PIVCs } \\
\text { secara rutin (setiap } 3 \text { hari) saya merasa } \\
\text { lelah }\end{array}$ & $\begin{array}{l}\text { Tidak Pernah } \\
\text { Pernah } \\
\text { Kadang-Kadang } \\
\text { Sering } \\
\end{array}$ & $\begin{array}{l}7(43.75) \\
1(6.25) \\
6(37.5) \\
2(12.5) \\
\end{array}$ \\
\hline $\begin{array}{l}\text { Saya jenuh harus melakukan pergantian } \\
\text { peripheral intravenous catheters / PIVCs } \\
\text { secara rutin (setiap } 3 \text { hari) }\end{array}$ & $\begin{array}{l}\text { Tidak Pernah } \\
\text { Pernah } \\
\text { Kadang-Kadang }\end{array}$ & $\begin{array}{c}8(50) \\
2(12.5) \\
6(37.5) \\
\end{array}$ \\
\hline $\begin{array}{l}\text { Selama ini saya merasa tenaga perawat } \\
\text { disini dibebankan dengan rutinitas } \\
\text { pergantian peripheral intravenous } \\
\text { catheters / PIVCs }\end{array}$ & $\begin{array}{l}\text { Tidak Pernah } \\
\text { Sering } \\
\text { Pernah }\end{array}$ & $\begin{array}{l}11(68.75) \\
4(25) \\
1(6.25)\end{array}$ \\
\hline $\begin{array}{l}\text { Saya merasa senang jika pergantian } \\
\text { peripheral intravenous catheters / PIVCs } \\
\text { dilakukan jika ada indikasi klinis }\end{array}$ & $\begin{array}{l}\text { Tidak Pernah } \\
\text { Pernah } \\
\text { Kadang-Kadang } \\
\text { Sering } \\
\text { Sering Sekali } \\
\end{array}$ & $\begin{array}{l}3(18.75) \\
3(18.75) \\
5(31.25) \\
2(12.5) \\
3(18.75) \\
\end{array}$ \\
\hline $\begin{array}{l}\text { Saya merasa senang jika pergantian } \\
\text { peripheral intravenous catheters / PIVCs } \\
\text { dilakukan karena indikasi klinis akan } \\
\text { mengurangi beban kerja saya }\end{array}$ & $\begin{array}{c}\text { Tidak Pernah } \\
\text { Kadang-Kadang } \\
\text { Sering } \\
\text { Sering Sekali }\end{array}$ & $\begin{array}{l}3(18.75) \\
5(31.25) \\
4(25) \\
2(12.5) \\
2(12.5)\end{array}$ \\
\hline $\begin{array}{l}\text { Selama ini saya merasa pergantian } \\
\text { peripheral intravenous catheters / PIVCs } \\
\text { secara rutin (setiap } 3 \text { hari) tidak perlu } \\
\text { dilakukan }\end{array}$ & $\begin{array}{c}\text { Tidak } \\
\text { Ya }\end{array}$ & $\begin{array}{l}7(43.75) \\
9(56.25)\end{array}$ \\
\hline
\end{tabular}

Tabel 4. Evaluasi beban kerja perawat $(n=16)$

D. Penilaian efisiensi biaya terhadap pemasangan IV

Berikut ini akan diuraikan contoh perhitungan efisiensi biaya pemasangan PIVCs dengan penggantian kateter IV yang $>3$ hari dengan atau tanpa indikasi klinis (pada tabel 2) yang berjumlah 17 orang yang diobservasi selama proses penelitian (15 pasian masih bertahan tanpa indikasi klinis, 2 pasien flebitis setelah 4 hari pemasangan dan setelah 10 hari pemasangan) dibandingkan dengan penggantian secara rutin (tabel 5) 


\begin{tabular}{|c|c|}
\hline $\begin{array}{c}\text { Penggantian Dengan } \\
\text { Indikasi Klinis }\end{array}$ & $\begin{array}{l}\text { Jika Penggantian Rutin Dengan Atau Tidak } \\
\text { Ada Indikasi Klinis }\end{array}$ \\
\hline $\begin{array}{l}\text { Perkiraan biaya ( } 1 \text { set infus Rp. } 40.000) \text { : } \\
\text { a. } 4-6 \text { hari }=1 \text { set infus untuk } 15 \text { pasien } \\
(15 \times \text { Rp. } 40.000)=\text { Rp. } 600.000 \\
\text { b. } 7-9 \text { hari }=1 \text { set infus untuk } 1 \text { pasien } \\
(1 \times \text { Rp. } 40.000)=\text { Rp. } 40.000 \\
\text { c. } 10-12 \text { hari }=1 \text { set infus untuk } 1 \text { pasien } \\
(1 \times \text { Rp. } 40.000)=\text { Rp. } 40.000 \\
\text { Total biaya: Rp. } 680.000\end{array}$ & $\begin{array}{l}\text { Perkiraan Biaya : } \\
\text { a. } 4-6 \text { hari }=2 \text { set infus / pasien, maka jika } 15 \\
\text { pasien }(15 \times 2 \times R p .40 .000)=\text { Rp. } 1.200 .000 \\
\text { b. } 7-9 \text { hari }=3 \text { set infuse untuk } 1 \text { pasien }(1 \mathrm{x} \\
(3 \times R p .40 .000)=\text { Rp. } 120.000 \\
\text { c. } 10-12 \text { hari }=4 \text { set infus untuk } 1 \text { pasien }(1 \times \\
\text { (4xRp. } 40.000)=\text { Rp. } 160.000 \\
\text { Total biaya: Rp. } 1.480 .000\end{array}$ \\
\hline
\end{tabular}

Selisih antara penggantian PIVCs secara rutin dengan indikasi klinis :

Total perkiraan biaya Rutin : Rp. 1.480 .000

Indikasi Klinis : Rp. $\quad 680.000$

Selisih : Rp. 800.000

Tabel 5. Efisiensi biaya penggantian PVICs

\section{PEMBAHASAN}

Tindakan pemasangan kateter IV merupakan bagian dari tindakan invasif yang kebanyakan membuat pasien menolak untuk dilakukan sebab membuat mereka tidak nyaman terutama saat pertama kakli pemasangan. Oleh karena tindakan pemasangan kateter IV adalah suatu tindakan invasif maka ada beberapa komplikasi yang dapat muncul seperti halnya infeksi pada area pemasangan atau flebitis, untuk itu penggantian kateter intravena segera dapat dilakukan. Penggantian kateter IV dapat dilakukan selain oleh karena adanya indikasi klinis seperti adanya infeksi, flebitis, oklusi, juga dapat dilakukan tanpa tanda adanya indikasi klinis. Hal ini biasanya dilakukan sesuai dengan SPO yang ada pada tiap-tiap instansi pelayanan kesehatan. Namun beberapa temuan bahwa pemnggantian kateter IV dapat dilakukan jika ada indikasi klinis sebab akan mengurangi tindakan invasif yang cukup menyakitkan pasien atau membuat pasien tidak nyaman, dapat menghemat waktu kerja perawat serta dapat menhemat biaya perawatan. Oleh karena itu sangat penting bahwa penggantian kateter IV dapat dilakukan jika hanya ada indikasi klinis.

Penggantian keteter $\leq 3$ hari terdapat 6 orang pasien dengan indikasi klinis (flebitis) dengan nilai 1 (sedikit sakit disekitar area IV). Keseluruhan pasien yang mengalami flebitis mendapatkan terapi antibiotik melalui IV. Hal ini sesuai dengan penelitian bahwa bahwa phlebitis kateter IV perifer terdeteksi dapat dikaitkan dengan salah satunya adalah penggunaan antibiotic (Pasalioglu \& Kaya, 2014). Sedangkan pelepasan PIVCs karena indikasi klinis (flebitis) setelah $>3$ hari pemasangan PIVCs yaitu 1 pasien flebitis setelah 10 hari pemasangan PIVCs dan 1 pasien flebitis setelah 4 hari pemasangan PIVCs. Sedangkan jumlah pasien yang terpasang PIVCs setelah $\geq 3$ tanpa phlebitis sebanyak 15 pasien. Penelitian P. Van Donk, Rickard, McGrail, \& Doolan (2009); Rickard et al., (2012), bahwa lama pemasangan kateter IV yang terpanjang pada penggantian kateter IV karena adanya indikasi klinis adalah tiga minggu atau 21 hari (491 jam) tanpa komplikasi. Terjadinya flebitis pada pasien yang terpasang kateter IV dapat dilakitkan dengan penggunaan antibiotik, oleh karena itu segera dapat dilakukan penggantiann kateter IV. Penggantian ini dilakukan dengan tujuan tidak lain adalah untuk memberikan kenyaman bagi pasaien.

Evaluasi dari segi kenyamanan pada pasien terhadap insersi IV bahwa keseluruhan pasien merasa nyaman bila dilakukan penggantian IV jika ada indikasi klinis. Penggantian kateter IV secara rutin akan memberikan rasa nyeri dan ketidaknyamanan pada pasien. Berdasarkan bukti penelitian 
yang ada, kebijakan saat ini untuk penggantian rutin $72-96$ jam tidak efektif dan perlu dilakukan kebijakan penggantian IV karena indikasi klinis. Penelitian oleh $\mathrm{Xu}, \mathrm{Hu}$, Huang, Fu, \& Zhang (2017), bahwa penggantian kateter IV dengan indikasi klinis dapat mengurangi ketidaknyamanan pasien. Dalam menerapkan penggantian IV karena indikasi klinis, ada hal penting yang harus yang dilakukan petugas yaitu memantau pemasangan IV secara teliti setiap hari untuk menilai tentang perlunya terapi IV dilanjutkan atau segera dilakukan penggantian/ pelepasan bila ditemukan indikasi klinis (Rickard, McCann, Munnings, \& McGrail, 2010).

Penilain terhadap beban kerja perawat bahwa pergantian secara rutin (setiap 3 hari) (tabel 4) tidak perlu dilakukan sebab menyebabkan waktu kerja bertambah dengan kata lain beban kerja bertambah. Beban kerja erat kaitannya dengan kinerja, yang mana berkaitan pula dengan performanya. Apabila beban kerja berlebih akan berpengaruh dengan kinerjanya, dimana hal ini berkaitan dengan tingkat kelelahan seseorang. Salah satu kinerja yang dimaksud adalah mentaati SPO yang berlaku di rumah sakit. Salah satunya adalah SPO pergantian infus secara rutin setiap 3 hari, padahal pergantian dengan indikasi klinis lebih efektif dan efisien seperti yang dikemukakan oleh $\mathrm{Xu}$ et al., (2017), bahwa penggantian kateter IV dengan indikasi klinis dapat mengurangi beban kerja perawat. Selain itu menurut (Wu \& Casella, 2013), bahwa pergantian selang intravena yang dilakukan secara klinis mengurangi beban kerja untuk staf klinis dan biaya perawatan kesehatan.

Penggantian kateter IV jika dilihat dari segi efisiensi biaya, hasil perhitungan menunjukkan bahwa terdapat selisih sekitar Rp. 800.000 jika penggantian kateter dilakukan jika hanya dengan indikasi klinis. Biaya penggantian kateter IV sangat erat kaitannya dengan perkiraan biaya perawatan yang harus dikeluarkan oleh pasien selama hari rawat termasuk cost RS pada umumnya. Oleh karena itu, penggantian kateter IV dapat dilakukan jika ada indikasi klinis sebab selain memberikan kenyamanan pada pasien juga menghemat biaya terhadap bahan set infus yang harus dibiayai oleh pasien maupun pihak RS. Suatu penelitian oleh P. Van Donk et al. (2009), bahwa pemasangan kateter IV hanya bila ada indikasi klinis akan menghemat biaya US $\$ 15,800$ pertahun $( \pm 189.000 .000)$ dan menghemat waktu perawat $( \pm 15$ menit). Penelitian lain bahwa penggantian kateter intravena perifer lebih aman jika dilakukan apabila ada indikasi klinis, karena menghemat sekitar 2 juta jam waktu kerja, dan sampai $\$ 60$ juta biaya perawatan rumah sakit (Keogh, 2013). Biaya yang dikeluarkan pada penggantin IV tiap 3 hari rata-rata \$A 41.02 ( $\mathrm{Rp} \mathrm{431.720)} \mathrm{per} \mathrm{pasien,}$ sedangakan jika penggantian dengan indikasi klinis hanya \$A 36.40 (Rp 383.107)(Webster et al., 2008).

Pentingnya tindakan penggantian kateter IV hanya dengan indikasi klinis dapat dilakukan pada semua instansi pelayana kesehatan yang melakukan perawatan medis klinis yang dapat membantu dalam proses perawatan maupun pengobatan bagi pasien. Tindakan ini jika dilakukan dengan indikasi klinis maka akan dapat meningkatkan kenyamanan bagi pasien, termasuk beban kerja perawat bisa berkurang serta biaya perawatan pasien dapat diminimalkan. Namun selama proses studi dilakukan ada beberapa hal yang terkait dengan penggantian kateter IV dimana pelepasan kateter IV tanpa komplikasi seperti pasien yang terlalu banyak gerak dan saat dilakukan pemasangan biasanya pasien menolak pada awalnya sebab merasa sakit saat pemasangan.

\section{KESIMPULAN}

Penggantian Peripheral intravenous catheters/PIVCs berdasarkan indikasi klinis akan 
menurunkan biaya perawatan, lama rawat, meningkatkan kenyamanan pasien serta dapat menurunkan beban kerja perawat.

\section{DAFTAR PUSTAKA}

Alekseyev, S., Byrne, M., Carpenter, A., Franker, C., Kidd, C., \& Hulton, L. (2012). Prolonging the life of a patient's IV: an integrative review of intravenous securement devices. Medsurg Nursing, 21(5), 285-292. Retrieved from https://www.ncbi.nlm. nih.gov/pubmed/23243786

Cicolini, G., Manzoli, L., Simonetti, V., Flacco, M. E., Comparcini, D., Capasso, L., ... Elfarouki, G. E. (2014). Phlebitis risk varies by peripheral venous catheter site and increases after 96 hours : a large multi-centre prospective study. Journal of Advanced Nursing, 11(70), 2539-2549. https://doi.org/10.1111/jan.12403

Danski, M. T. R., Oliveira, G. L. R. de, Johann, D. A., Pendrolo, E., \& Vayego, S. A. (2015). Incidence of local complications in peripheral venous catheters and associated risk factors, 28(6), 517-523. https://doi. org/http: / /dx.doi.org/10.1590/19820194201500087

Donk, P. Van, Rickard, C. M., McGrail, M. R., \& Doolan, G. (2009). Routine Replacement versus Clinical Monitoring of Peripheral Intravenous Catheters in a Regional Hospital in the Home ... Catheters in a Regional Hospital in the Home Program : A Randomized controlled Trial, 30(December 2014). https://doi.org/10.1086/599776

Dychter, S. S., Gold, D. A., Carson, D., \& Haller, M. (2012). Intravenous therapy: A review of complications and economic considerations of peripheral access. Journal of Infusion Nursing, 35(2), 84-91. https://doi. org/10.1097/NAN.0b013e31824237ce

Gorski, L., Hadaway, L., Hagle, M. E. McGoldrick, M., Orr, M., \& Doellman, D. (2016). Infusion Therapy Standards of Practice. Journal of Infusion Nursing, 39(1), 4-169. Retrieved from www. journalofi nfusionnursing.com

Gorski, L., \& Phillips, L. D. (2014). Manual of I.V. Therapeutics: Evidence-Based Practice for Infusion Therapy 6th Edition (6th Editio). Philadelphia: Davis Company.

Jacob, A., R, R., \& Tarachnand, J. (2014). Buku ajar clinical nursing procedures (2nd ed.). Tangeran Selatan: Binarupa Aksara.

Keogh, S. (2013). New research: Change peripheral intravenous catheters as clinically indicated, not routinely. JAVA Journal of the Association for Vascular Access, 18(3), 153-154. https://doi. org/10.1016/j.java.2013.03.005

Line, C. (2010). Discomfort Verbal Rating Scale patient. Retrieved December 8, 2017, from http://www.thecomfortline.com/ resources/cq.html

McCallum, L., \& Higgins, D. (2012). Care of peripheral venous cannula sites. Nursing Times, 108(34-35), 12, 14-15. https:// doi.org/10.1016/j.java.2014.09.001

Morrison, K., \& Holt, P. K. E. (2015). The Effectiveness of Clinically Indicated Replacement of Peripheral Intravenous Catheters: An Evidence Review With Implications for Clinical Practice, 4(12), 187-198. https://doi.org/10.1111/ wvn. 12102

Pasalioglu, K. B., \& Kaya, H. (2014). Catheter indwell time and phlebitis development during peripheral intravenous catheter administration, 30(4), 725-730. https:// doi.org/http://dx.doi.org/10.12669/ pjms.304.5067

RCN (Royal College of Nursing). (2010). Standards for infusion therapy. Retrieved from www.rcn.org.uk

Rickard, C. M., Marsh, N., Webster, J., Playford, E. G., McGrail, M. R., Larsen, E., ... Fraser, J. F. (2015). Securing All intraVenous devices Effectively in hospitalised patients-the SAVE trial: study protocol for a multicentre randomised controlled trial. BMJ Open, 5(9), e008689. https:// doi.org/10.1136/bmjopen-2015-008689

Rickard, C. M., McCann, D., Munnings, J., \& McGrail, M. R. (2010). Routine resite of peripheral intravenous devices every 3 days did not reduce complications compared with clinically indicated resite: a randomised controlled trial. BMC Medicine, 8(2), 53-62. https://doi. org/10.1186/1741-7015-8-53

Rickard, C. M., Webster, J., Wallis, M. C., Marsh, N., McGrail, M. R., French, V., ... Whitby, M. (2012). Routine versus clinically indicated replacement of peripheral intravenous catheters: A randomised controlled equivalence trial. The Lancet, 380(9847), 1066-1074. https://doi. org/10.1016/S0140-6736(12)61082-4

Webster, J., Clarke, S., Paterson, D., Hutton, A., Dyk, S. Van, Gale, C., \& Hopkins, T. (2008). Routine care of peripheral intravenous catheters versus, 1, 1-6. https://doi.org/10.1136/bmj.a339

Wu, M. A., \& Casella, F. (2013). Is clinically indicated replacement of peripheral catheters as safe as routine replacement in preventing phlebitis and other complications?, (8), 443-444. https:// doi.org/10.1007/s11739-013-0940-Z

Xu, L., Hu, Y., Huang, X., Fu, J., \& Zhang, J. (2017). Clinically indicated replacement versus routine replacement of peripheral venous catheters in adults: A nonblinded, cluster-randomized trial in China. International Journal of Nursing Practice, 1-8. https://doi.org/10.1111/ijn.12595 